\title{
SECURITY EDUCATION FOR TIMES OF NETWAR AND PEACE
}

\author{
Jaroslav Dockal \\ Brno Military Academy, K303, Kounicova 65, 61200 Brno, Czech Republic, \\ jdockal@vabo.cz
}

\begin{abstract}
Security education has a lot of things in common all over world but there are some differences that distinguish richer countries from poorer ones and military education from civilian contexts. Although the Internet partially removes some of the handicap of restrictions on international personal contact, it does not fully eliminate it. In spite of this, certain aspects of security education in a small country would be interesting for participants of such an important conference as WISE 3/WECS. That is why this paper describes system of security education in the Czech Republic and discusses specific procedures used at Brno Military Academy for training in operative decisionmaking. The paper supplement comprises two examples of solutions to critical situations by means of Aprisma's SPECTRUM Security Manager (SSM).
\end{abstract}

Key words: Security education, military education, subject, lifelong learning, hacker, warrior for netwar, decision-making, scenario, SSM

\section{SECURITY EDUCATION IN THE CZECH REPUBLIC}

This paper will start with a description of the situation of security education in the Czech Republic, particularly at the universities in four major cities: Prague, Brno, Plzen and Ostrava. This analysis should give us an answer for the question: Does the Czech military need a special education origram in the area of security or is it better to recruite graduates of civilian universities? 


\subsection{Prague}

The oldest Czech University is Charles University in Prague, founded in 1348. It is paradoxical that often ancient universities have a special liking for a modern education. At Charles University, security education is offered by the College of Mathematics and Physics in the subject Protection of Information and in the seminars: Mathematical Principles of Information Activity, Security of Information Systems in Practice and Implementations of Cryptography. The seminar form of classes eliminates the rigorousness of classic teaching. The high quality of teachers creates a solid base for cryptography classes. It is possible to follow a program of study, oriented on cryptography, with a statement this field of study written on graduates' diplomas. There are inexhaustible opportunities to use Microsoft software for security education; Charles University devotes the subject such as Programming for Windows to exploring these problems. For teaching of practical problems external experts are used; the University exploits the reality of the fact that the majority of important security companies in the country are located in Prague.

The College of Electrical Engineering of the Czech Technical University provides security education in the subjects Mathematical Fundamentals of Cryptography (Department of Mathematics), Data Protection in Informatics (Department of Telecommunications Engineering) and Applied Cryptography (Department of Computer Science). We can also encounter security problems in lectures of other subjects, especially in Computer Architecture, Computer Networks, Distributed Systems and Operating systems. In other words, security problems are integrated into the syllabi of other subjects, so that students understand that not only are functionality and reliability important for modern technical system design, but security is also. An example of this approach is the development of encryption hardware with the involvement of the students of the college. This college does not prepare separate branch of study, because the small number of specialists educated at Charles University is sufficient for the requirements of such a small country as the Czech Republic is.

The third important university in Prague is University of Economics. The students at this university are not oriented to the technical problems of security, so much as they are to the areas of security principles of Internet and laws and ethics, mainly in the area of trade. In 2002 the compulsory subject Information Technology Security was started. 


\subsection{Brno}

The second most important center of college education in the Czech Republic is Brno, with six universities. Brno is the largest city in Moravia, but more will be said about this university later in the paper. In addition to Brno Military Academy there are only two other universities in Brno that are important in the area of security. These universities are smaller than the ones in Prague and have fewer branches of study, but security education is not at a lower level.

The College of Informatics at Masaryk University Brno offers a whole spectrum of subjects in the area of information security. The subject Data Protection and Information Privacy is offered as an introductory course to new students of the Bachelors program. Those students who are interested in a deeper knowledge of cryptography problems have rich choice of lectures and seminars, such as Security of Information Technologies, Coding Cryptography and Cryptographic Protocols, Applied Cryptography, Authentication and Access Control and Essentials of Law for Informatics and Information Law. If students choose to study in the field of Information Technology Security then the majority from these subjects are compulsory and this field of study is stated on the diploma of graduates. Students who study for a master's degree in Computer Systems, Information Systems and Theoretical Informatics attend lecture from Information Security. Security applications are integrated into the subjects System Design and Administration, Computer Networks and others.

Those students, who are interested in a deeper study of the mathematical basics of cryptography, have an opportunity to do it within the bounds of other subjects offered by the College of Science at Masaryk University Brno. The focus of this study is on the complex conception of security problems in the sphere of Information Technology, mathematics and law, and some subjects are taught wholly or partially in English.

The College of Information Technology at the Brno University of Technology is a new college created with a goal to avoid the rigidity of already existing colleges. It incorporates security problems into classes on two comprehensive subjects: Information Systems Security and Cryptography. These subjects are electives for those students who are interested in studying these problems.

Both in Prague and Brno, study is based on the credit system. Students can collect credits, which can be used for degrees at both universities. Both in Prague and Brno the schools cooperate in preparing combined programs of study. The two other university centers in Plzen and Ostrava, in which the lectures on security are given on a large scale only at one school in town, do not offer combined programs of study. 


\subsection{Plzen/Ostrava}

The town of Plzen is known around the world mainly for its beer (Pilsner). This town also has a modern University of West Bohemia, whose former students have established a group of very enterprising security firms, which also operate in the United States. The aim of the Technical University is to use results of these firms in their research. Security models and fundamentals of cryptography are lectured there in the special subjects Computer Security, and security applications in subjects Operating Systems, Distributed Systems and Computer Networks.

The Faculty of Electrical Engineering and Informatics at Ostrava Technical University concentrates security education into one elective subject: Security in Information Technology, which is offered to students of the Information Engineering branch.

We can come to the particular conclusion that different goals of these universities results in different structure and contents of the subjects, but there is also another trend: convergence of universities and advanced technical study.

In conclusion the answer to the question: Does the Czech military need a special education origram in the area of security or is it better to recruite graduates of civilian universities? Is as follows. Civilian universities in the Czech Republic have a wide range of graduates with different levels and styles of education. This is very useful in the civilian sector and their future employers will welcome a rich selection of graduates' profiles. Theoretical base is in this system good (in the opinion of author of paper) but practical application of this knowledge is very diverse. The Army educational system on the other hand is unified including security methodology, software and hardware. Enlistment of the civilian graduates means not only having to teach them military duties, but also to integrate their knowledge in security and training to that used in military security equipment. However, instead of trying to integrate civilian graduates after graduation we proceed in another way. This way will be described in the next chapter.

\section{APPROACH TO SECURITY EDUCATION AT BRNO MILITARY ACADEMY}

This part of this article describes specific approaches to security education at Brno Military Academy and involves two scenarios of a critical situation used in the education process there. 


\subsection{Security Education}

After the fall of the Iron Curtain and admission of the Czech Republic to NATO, our military educational system underwent a continuous series of reforms. On the one hand, this volatility is an obstacle to conceptual effort, but on the other hand it is exploited for promotion of new ideas in education.

After the fall of the Iron Curtain and admission to NATO, our military educational system underwent a continuous series of reforms. On the one hand, this volatility is an obstacle to conceptual effort, but on the other hand it is exploited for promotion of new ideas in education.

Security is at present lectured at two colleges, one with a command orientation and another with a technical orientation. At the Command College information security is one of many types of security. At the technical college information security is an important component in the study of Special Communication Systems and Special Information Systems. Classes in Special Communications Systems are concentrated on encryption of data transmissions.

Our students complete a three-year bachelor study program and after some practice as an administrator a two years master's study program. They receive elementary fundamentals of information security in the course Fundamentals of Informatics. During the bachelor program, students also have to pass an exam for the special subject Computer Security, which involves security models and standards, methodology of designing secure systems, e-commerce and theoretical foundations of cryptography (algorithms and protocols, verification and validation). Other security aspects are taught in other subjects: Operating Systems (Unix and Windows security), Computer Programming (malicious code, writing secure code, antiviral software), Computer Networks (attack and defence, routers ACLs, firewalls, VPNs including BGP/MPLS VPNs, IDS, PKI), Database Systems (access control, polyinstantiation), Computer Hardware (tamper resistance, emission security, biometric techniques and smart cards), Web Application Programming (Java, PHP and ASP security) and Internet and Intranet Technology (XML security).

The traditional education system in our country is based on practice "from theoretical fundamentals to applied disciplines". The completion of the bachelor's program is a culmination of this practice. After one or more years of practice in military units as a system, network, web, database or security administrator students have enough basic practical experiences and it is the right moment to give them the opportunity to improve their knowledge through a masters program.

In the masters program we lay great emphasis on merging and integrating partial knowledge and proficiencies; graduates must be capable resolving 
demanding complex problems. We also put stress on creative solutions to problems. This approach is almost impossible without adequate hardware and software that are capable of reflecting the methods and principles being taught.

Study at our Military Academy does not finish at the graduation ceremony. We are preparing "lifelong learning" in the area of information technology and security will be a part of it. One branch will be for commanders and staff officers and a second for specialists in IT. We prepare security experts at these three levels:

- Strategic level: they should be able to design complex security projects, in particular risk analysis, to create and revise security policy (revise whether it corresponds to the actual requirements), to plan and organize the defense of important military information systems and present qualified requests for the purchase of the new technology and devices.

- Supervisor level: they should be able to revise configuration, organize penetration tests as well as training and practice information units, build surrogate targets and solve new security problems as experts.

- Operation level: they should be able to configure firewalls, routers, intruder detection systems, servers and other devices and in real time analyse logs coming from them.

Operation level is the subject of bachelor's level of study, supervisor level is the subject of master study and strategic level is the subject of the postgraduate study. More theoretical security problems are solved as $\mathrm{PhD}$ projects and we plan to increase the number of $\mathrm{PhD}$ candidates in the future. "Lifelong learning" is a very demanding matter because it is difficult to establish the start, end or sequence of courses. In addition, IT is continually progressing and courses must be revised.

We cooperate very intensely with companies in the Czech Republic that are active in the area of IT security. For example, we cooperate with the company ICZ (http://www.i.cz/en/) in the area of researching side-channel attacks, with AEC (http://www.aec.cz/us/default.asp) in area of building PKI, we use the source code of the Kernun firewall company Trusted Network Solutions in laboratories and we cooperate with GiTy (http://www.gity.cz/index_e.php) in preparing class scenarios. We use Cisco security bundle, Symantec and NAI software and Hewlett-Packard management software for our laboratories. Once every two years we organize NATO registered PfP/PWP (Partnership for Peace / Partnership Work Programme) International Scientific Conference "Security and Protection of Information", see http://www.vabo.cz/spi/ defaulten.htm. 


\subsection{Use of Scenarios in Security Education}

The application of information security is the similar to the art of war. Analogously, as in military affairs, in information war success depends on the technique used, systematic training and leadership to fight. Modern war is still based more and more on using highly sophisticated weaponry, often connected into networks. But how can students get experience in this area? We have some experiences of hacker attacks but is this enough to win a network war?

The main motivation of hackers is usually exhibition. For example, Czech hackers placed a figure of a famous Czech shirker soldier Svejk (similar to Beetle Baily) on the web portal of the General Staff of Czech Army. This kind of joking, typical for hacker, will not satisfy a terrorist. The aim of a terrorist attack is total destruction. While a hacker's aim is to stay anonymous, a terrorist is capable of self-sacrifice. A hacker's activity is often a game or question of prestige for him, but it's a matter of life and death for a terrorist.

Several years ago it was common to look on network security in terms of binary logic ("realm of evil" and "realm of good"), in our military sphere if was usual to differentiate only between unsatisfied networks and satisfied networks behind reliable firewall. Possible intrusion was in this interpretation any incident that we had to analyze and take appropriate measures against. In contrast the modern approach to network security is proactive, based on predicting and neutralizastioning attacks. But this approach requires more trained and quick-witted staff at the operation level.

Typical system administration is a question day-to-day maintenance, but defence against terrorist attack requires procedures and techniques used in crisis management. Anti-terrorist defence is based on making an operational choice of variants, which have been prepared for and well rehearsed in advance. For this paper two of our simplest scenarios which are used for training Military Academy bachelor students were chosen. In these scenarios Aprisma's SSM (http://www.aprisma.com/products/security.shtml, ref. 1. and 2.) was used and they were prepared in cooperation with David C. Hajicek from the Company GiTy. The goal of these and other scenarios is to prepare our students for both typical as well as unusual situations and so make them able to solve problems in conditions where they have to deal with a flood of information and lack of time. 


\subsection{Scenario 1:}

\subsubsection{Assignment}

On a computer network a user has been discovered who seems dangerous. He executes undesirable operations that might cause a security incident. Your task is to find this user, specify his IP address and the location of his computer, if it allowed by system security policy. Specify which operation this user has executed and assess the degree of danger of the incident and decide what procedure to fellow next.

\subsubsection{Possible Method of Solution}

Start SPECTRUM Security Manager (SSM) see graph of events and identification of security incident. Specify IP address of attacking computer. By the color of the alarm decide if the attacker's activities will be audited or if his activities will be denied. Look at the schema of the computer network and specify the location of his computer.

Try to use some of standard Intruder Detection Systems (IDS). Although all information is full and correct, you will not receive enough information to solve this problem, as shown in Figure 1.

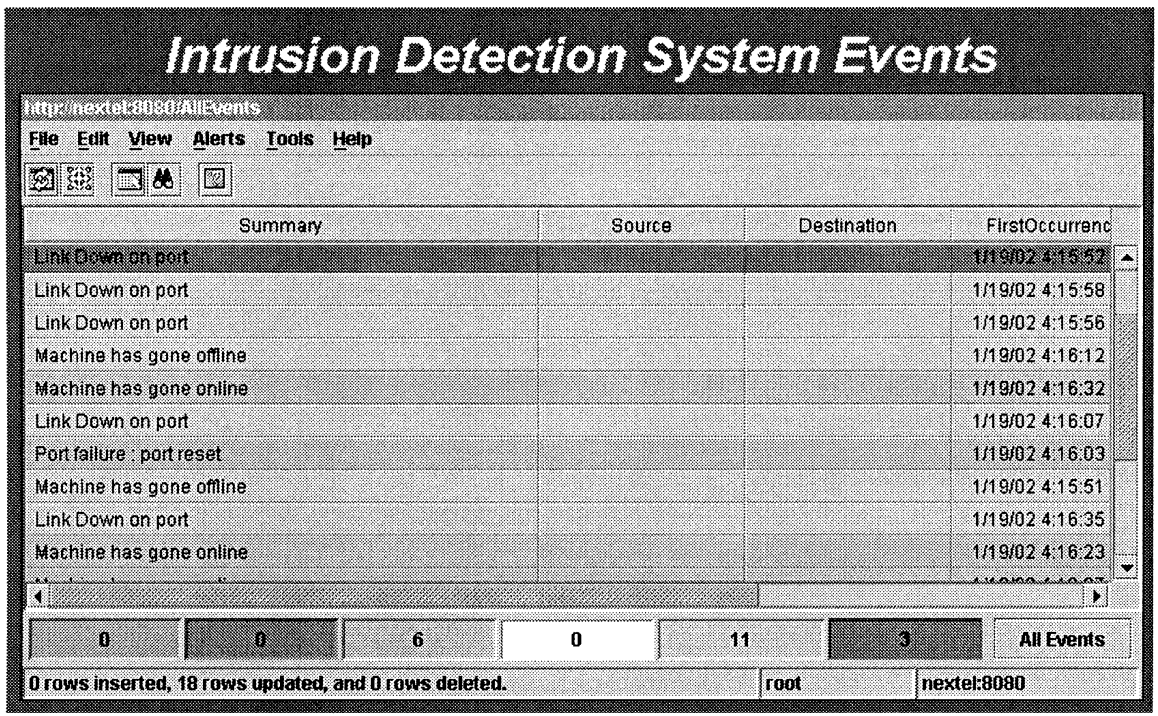

Figure 1. Solution of the problem by IDS 
Also use the event graph of SSM. In Figure 2 we see a server (red circle on the top of screen), three IDS and security incident: The user with IP address 141.190.129.113 (blue circle in the below left-hand corner of the screen) frequently and within a short period of time tries to access the group of stations. He is maybe looking for some shared files or testing which vulnerable services are running (for example telnet or ftp). In this example we will start with audit because risk value, which was identified by the color of circle, is low.

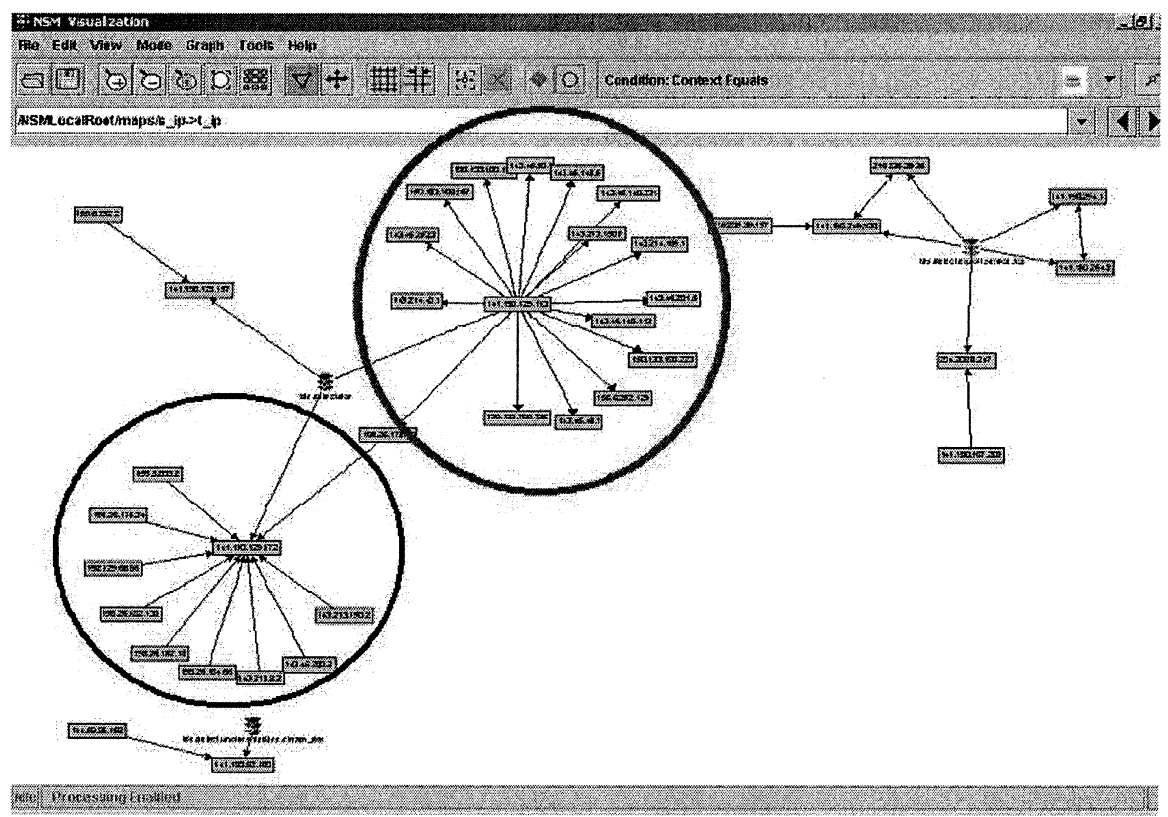

Figure 2. Dynamic event graph in SSM

We will make a final decision about what action to take depending on the attacker's previous activity. We use the tool „Reporting Tool“ (Figure 3) to identify if our user had other security incidents during his most recent activity. 


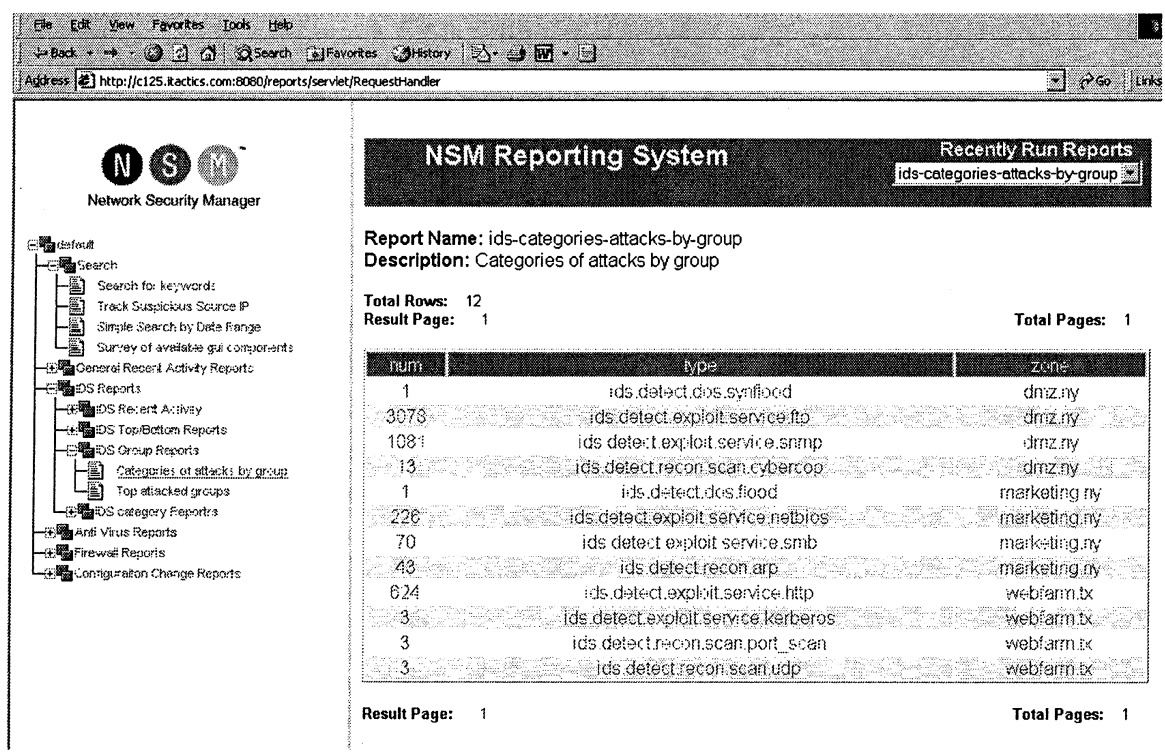

Figure 3. Reporting Tool

The Reporting Tool gives us information about security events in the last five minutes. In Figure 3 you can see that in the last 5 minutes no security incident was reported from network 141.190.129.0. This would mean that this attack was accidental and without serious influence on security.

\section{$2.4 \quad$ Scenario 2}

\subsubsection{Assignment}

Your task is to inspect the functionality of all security devices in a computer network. Specify security incidents in a given time period and suggest what measures should be taken.

\subsubsection{Possible Method of Solution}

Open dialog window of SSM (Figure 4), use "Reporting Tool" (Figure 3 ), generate a report for the last 5 minutes, specify security problems, and suggest countermeasures depending on security policy of the system. 


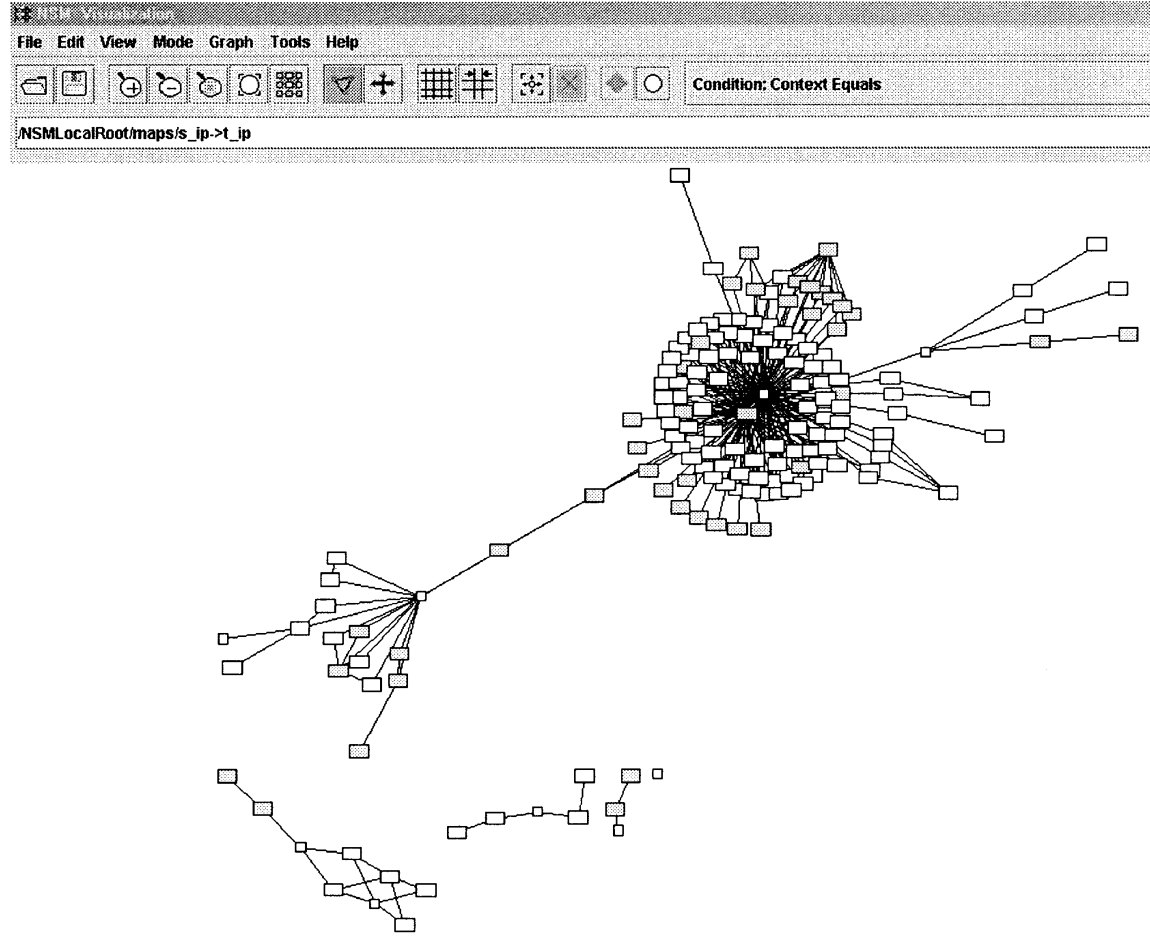

Figure 4. Dynamical graph SSM

Use filters and choose output (database, IDS, script execution).

Success of using this type of scenarios is dependent on the student having a good preliminary knowledge of the security tools (such as SSM) and experience with this type of job.

\section{CONCLUSION}

Military security education is in many respects the same as in the civilian sector, but in some respects unique. We cooperate with our civilian universities and learn from their approach to education, but we do not copy them. Apart from other things this paper has described, we use specific procedures for training in operative decision-making based on scenarios to solve exceptional situations. 


\section{REFERENCES}

1. User's Manual of iNotary. infocount Brno 2002.

2. Internal Documentation of iNotary. GiTy Brno 2002. 